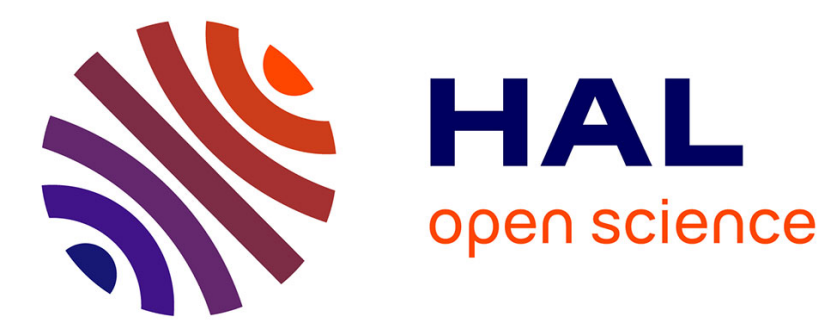

\title{
Reduced-order observer-based point-to-point and trajectory controllers for robot manipulators
}

Mohamed Fayçal Khelfi, Michel Zasadzinski, Hugues Rafaralahy, Edouard Richard, Mohamed Darouach

\section{- To cite this version:}

Mohamed Fayçal Khelfi, Michel Zasadzinski, Hugues Rafaralahy, Edouard Richard, Mohamed Darouach. Reduced-order observer-based point-to-point and trajectory controllers for robot manipulators. Control Engineering Practice, 1996, 4 (7), pp.991-1000. hal-00143943

\section{HAL Id: hal-00143943 https://hal.science/hal-00143943}

Submitted on 28 Apr 2007

HAL is a multi-disciplinary open access archive for the deposit and dissemination of scientific research documents, whether they are published or not. The documents may come from teaching and research institutions in France or abroad, or from public or private research centers.
L'archive ouverte pluridisciplinaire HAL, est destinée au dépôt et à la diffusion de documents scientifiques de niveau recherche, publiés ou non, émanant des établissements d'enseignement et de recherche français ou étrangers, des laboratoires publics ou privés. 


\title{
REDUCED-ORder OBSERVER-BASED POINT-TO-POINT AND TRAJECTORY CONTROLLERS FOR ROBOT MANIPULATORS
}

\author{
M.F. KHELFI ${ }^{\dagger}$, M. ZASADZINSKI ${ }^{\dagger}$, H. RAFARALAHY ${ }^{\dagger}$, E. RICHARD ${ }^{\dagger} \ddagger$ \\ and M. DAROUACH ${ }^{\dagger}$ \\ † CRAN - ACS - CNRS URA 821 - Université Henri Poincaré-Nancy I \\ 186 rue de Lorraine, 54400 Cosnes-et-Romain, FRANCE \\ Fax : (33) 82239793 - Email : preudhom@acturus.ciril.fr \\ \$ INRIA Lorraine - Université de Metz - 4 rue Marconi, 57070 Metz, FRANCE
}

\begin{abstract}
This paper presents a design procedure for a reduced-order observer-based controller dedicated to $n$-joint robot manipulators. It is assumed that only the joint angular positions are measured. The joint angular velocities are estimated via an exponential reduced-order observer. Two types of control laws based on this observer are studied: point-to-point control with gravity compensation and trajectory control. Sufficient conditions to ensure the closed-loop stability are given. Performances of the reduced-order observer used with these two control laws are illustrated in a simulation study of a two-degrees-of-freedom robot manipulator.
\end{abstract}

Keywords: Robot manipulators; exponential reduced-order observers; controller design; asymptotic stability.

\section{INTRODUCTION}

In most cases, the robot controllers presented in the literature are based on complete state feedback. But in many practical situations, the joint angular velocities are obtained either by differentiating the measured joint angular positions or through tachometers. In both cases, the velocity signal is contaminated by noise. This can degrade the performance of closed-loop robot systems. To overcome this problem, state estimators are used to reconstruct the joint angular velocities (Berghuis and Nijmeijer, 1993; Canudas de Wit, et al., 1992; Nicosia and Tomei, 1990).

This paper proposes a new exponential reduced-order observer for a class of nonlinear systems, including robot manipulator dynamics. The design of this observer is straightforward, with no need for a nonlinear change of coordinates.

The paper is organised as follows. Section 2 describes the dynamic model of a rigid robot manipulator. Section 3 is devoted to the reduced-order observer design. Sufficient conditions are given for the exponential convergence of the observer error. In Section 4, this observer is used with two classical state feedback controllers: point-to-point control with gravity compensation and trajectory control (Lewis, et al., 1993; Nicosia and Tomei, 1990; Spong and Vidyasagar, 1989; Tagekaki and Arimoto, 1981). For these two reduced-order observer-based controllers, sufficient conditions for the closed-loop asymptotic stability are given. In Section 5, a simulation with a twodegrees-of-freedom robot manipulator (Berghuis and Nijmeijer, 1993) is presented. The efficiency of the proposed reduced-order observer-based control schemes is shown by a comparison with the same state feedback controllers using the full-order state estimator proposed in (Deza and Gauthier, 1991) and (Deza, et al., 1993). A first version of this work has been previously published in an IFAC Conference (Khelfi, et al., 1995).

\section{SYSTEM DESCRIPTION AND STRUCTURAL PROPERTIES OF THE ROBOT MANIPULATOR}

The dynamics of a n-joint rigid robot manipulator can be described by a second-order nonlinear vector differential equation (Spong and Vidyasagar, 1989)

$$
\phi(q) \ddot{q}+C(q, \dot{q}) \dot{q}+F_{V} \dot{q}+G(q)=\Gamma
$$

where $\mathrm{q} \in \mathbb{R}^{\mathrm{n}}$ is the vector of joint angular positions, $\Gamma \in \mathbb{R}^{\mathrm{n}}$ is the vector of applied joint torques, $\phi(\mathrm{q}) \in \mathbb{R}^{\mathrm{n} \times \mathrm{n}}$ is the symmetric positive definite inertia matrix, $\mathrm{C}(\mathrm{q}, \dot{\mathrm{q}}) \dot{\mathrm{q}} \in \mathbb{R}^{\mathrm{n}}$ is the Coriolis and centrifugal 
torque vector, $\mathrm{G}(\mathrm{q}) \in \mathbb{R}^{\mathrm{n}}$ is the gravity vector, and $\mathrm{F}_{\mathrm{v}} \in \mathbb{R}^{\mathrm{n} \times \mathrm{n}}$ is the diagonal matrix of the viscous friction coefficients.

In the following, the structural properties of each of the terms in the robot dynamics equation (1) are given (Koditschek, 1984). These properties will offer a great deal of insight which will be used to derive robot control schemes.

P 1:

P 2:

P3:

P4:

$$
\varphi_{1} I_{n} \leq \phi(q) \leq \varphi_{2} I_{n} \text { for some strictly positive constants } \varphi_{1} \text { and } \varphi_{2} \text {. }
$$

$\dot{\phi}(\mathrm{q})-2 \mathrm{C}(\mathrm{q}, \dot{\mathrm{q}})$ is a skew symmetric matrix. $\mathrm{C}\left(\mathrm{q}, \mathrm{x}_{1}\right) \mathrm{x}_{2}=\mathrm{C}\left(\mathrm{q}, \mathrm{x}_{2}\right) \mathrm{x}_{1}$ for all $\mathrm{x}_{1}, \mathrm{x}_{2} \in \mathbb{R}^{\mathrm{n}}$

$$
\|\mathrm{C}(\mathrm{q}, \mathrm{x})\| \leq \mu\|\mathrm{x}\| \text { for all } \mathrm{x} \in \mathbb{R}^{\mathrm{n}}
$$

Notice that $\|$. || denotes the Euclidean vector norm. Applied to a matrix, $\|$. \| corresponds to the p-2 induced norm (Lancaster and Tismenetsky, 1995).

\section{REDUCED-ORDER OBSERVER DESIGN}

\subsection{State-space representation}

A first step in the design of an output feedback controller for the robot system (1) is the reconstruction of the joint angular velocities using the joint angular position measurements. The proposed observer is of reduced order and is based on a state-space observable canonical form of (1) given by

$$
\dot{x}=A x+f(x)+h(x) u .
$$

Since the matrix $h(x)$ is composed only of the elements of the inverse inertia matrix $\phi^{-1}(q)$ which depends exclusively on the joint angular positions, then the state vector $\mathrm{x}$ can be replaced by the measured output vector $\mathrm{y}$; thus eq. (6) can be rewritten as

with, for $\mathrm{i}=1, \ldots, \mathrm{n}$,

$$
\begin{gathered}
\dot{x}=A x+f(x)+h(y) u \\
y=H x
\end{gathered}
$$

$$
\begin{gathered}
\mathrm{A}=\operatorname{diag}\left(\mathrm{A}_{\mathrm{i}}\right) \text { and } \mathrm{A}_{\mathrm{i}}=\left[\begin{array}{ll}
0 & 1 \\
0 & 0
\end{array}\right] \\
\mathrm{H}=\operatorname{diag}\left(\mathrm{H}_{\mathrm{i}}\right) \text { and } \mathrm{H}_{\mathrm{i}}=\left[\begin{array}{ll}
1 & 0
\end{array}\right] \\
\mathrm{f}(\mathrm{x})=\left[\ldots \mathrm{f}_{\mathrm{i}}(\mathrm{x})^{\mathrm{T}} \ldots . .\right]^{\mathrm{T}} \text { and } \mathrm{f}_{\mathrm{i}}(\mathrm{x})=\left[\begin{array}{l}
0 \\
\left.\alpha_{\mathrm{i}}(\mathrm{x})\right]^{\mathrm{T}}
\end{array}\right. \\
\mathrm{h}(\mathrm{y})=\left[\ldots . \mathrm{h}_{\mathrm{i}}(\mathrm{y})^{\mathrm{T}} \ldots . .\right]^{\mathrm{T}} \text { and } \mathrm{h}_{\mathrm{i}}(\mathrm{y})=\left[\begin{array}{c}
0 \\
\mathrm{~b}_{\mathrm{i}}(\mathrm{y})
\end{array}\right]
\end{gathered}
$$

where $\mathrm{x}^{\mathrm{T}}=\left[\ldots \mathrm{x}_{\mathrm{i}}^{\mathrm{T}} \ldots\right], \mathrm{x}_{\mathrm{i}}=\left[\mathrm{q}_{\mathrm{i}} \dot{q}_{\mathrm{i}}\right]^{\mathrm{T}}, \mathrm{u}=\Gamma, \alpha_{\mathrm{i}}(\mathrm{x})$ is the ith component of the vector

$\phi^{-1}(\mathrm{q})\left(-\mathrm{C}(\mathrm{q}, \dot{\mathrm{q}}) \dot{\mathrm{q}}-\mathrm{F}_{\mathrm{v}} \dot{\mathrm{q}}-\mathrm{G}(\mathrm{q})\right)$, and $\mathrm{b}_{\mathrm{i}}(\mathrm{y})$ is the ith row of the inverse inertia matrix $\phi^{-1}(\mathrm{q})$ with $\mathrm{x}_{\mathrm{i}} \in \mathbb{R}^{2}$, $\mathrm{x} \in \mathbb{R}^{2 \mathrm{n}}, \mathrm{u} \in \mathbb{R}^{\mathrm{n}}, \mathrm{y} \in \mathbb{R}^{\mathrm{n}}, \alpha_{\mathrm{i}}(\mathrm{x}) \in \mathbb{R}, \mathrm{f}_{\mathrm{i}}(\mathrm{x}) \in \mathbb{R}^{2}, \mathrm{~b}_{\mathrm{i}}^{\mathrm{T}}(\mathrm{y}) \in \mathbb{R}^{\mathrm{n}}$, and $\mathrm{h}_{\mathrm{i}}(\mathrm{y}) \in \mathbb{R}^{2 \times \mathrm{n}}$.

One can see that the pair $(\mathrm{A}, \mathrm{H})$ is observable.

Since $\alpha_{\mathrm{i}}(\mathrm{x})$ is a combination of cosine and sine functions (robot with revolute joints), $\mathrm{f}(\mathrm{x})$ is Lipschitz in all domain $\mathcal{D}_{0}$ where $\dot{\mathrm{q}}$ is bounded, i.e. $\mathrm{f}(\mathrm{x})$ satisfies the following property

P5:

$$
\left\|f\left(x_{1}\right)-f\left(x_{2}\right)\right\| \leq \kappa\left\|x_{1}-x_{2}\right\| \quad \text { for all } x_{1}, x_{2} \in \mathcal{D}_{0}
$$

where $\mathcal{D}_{0}=\left\{\mathrm{x} \in \mathbb{R}^{2 \mathrm{n}} /\|\dot{\mathrm{q}}\|<\mathrm{V}_{\mathrm{M}}\right\}$, with $\mathrm{V}_{\mathrm{M}}$ is a given positive scalar and $\kappa$ is the Lipschitz constant.

\subsection{Observer design}

To reconstruct the joint angular velocities of a robot manipulator, a reduced-order observer, which ensures an exponential convergence of the state observation error $(\hat{x}-\mathrm{x})$, is proposed. This observer has the following statespace model

$$
\dot{z}=N z+L y+g(z, y)+j(y) u
$$




$$
\begin{gathered}
\hat{x}=M z+E y \\
z=T \hat{x}
\end{gathered}
$$

where $\mathrm{N}=\operatorname{diag}\left(\mathrm{N}_{\mathrm{i}}\right), \mathrm{L}=\operatorname{diag}\left(\mathrm{L}_{\mathrm{i}}\right), \mathrm{M}=\operatorname{diag}\left(\mathrm{M}_{\mathrm{i}}\right), \mathrm{E}=\operatorname{diag}\left(\mathrm{E}_{\mathrm{i}}\right), \mathrm{T}=\operatorname{diag}\left(\mathrm{T}_{\mathrm{i}}\right), \mathrm{g}(\mathrm{z}, \mathrm{y})=\left[\ldots . \mathrm{g}_{\mathrm{i}}(\mathrm{z}, \mathrm{y}) \ldots . .\right]^{\mathrm{T}}$, $\mathrm{j}(\mathrm{y})=\left[\ldots . \mathrm{j}_{\mathrm{i}}(\mathrm{y})^{\mathrm{T}} \ldots . .\right]^{\mathrm{T}}$ and $\mathrm{z} \in \mathbb{R}^{\mathrm{n}}, \mathrm{u} \in \mathbb{R}^{\mathrm{n}}, \hat{\mathrm{x}} \in \mathbb{R}^{2 \mathrm{n}}, \mathrm{N}_{\mathrm{i}} \in \mathbb{R}, \mathrm{L}_{\mathrm{i}} \in \mathbb{R}, \mathrm{M}_{\mathrm{i}} \in \mathbb{R}^{2}, \mathrm{E}_{\mathrm{i}} \in \mathbb{R}^{2}, \mathrm{~T}_{\mathrm{i}}^{\mathrm{T}} \in \mathbb{R}^{2}$, $\mathrm{g}_{\mathrm{i}}(\mathrm{z}, \mathrm{y}) \in \mathbb{R}$, and $\mathrm{j}_{\mathrm{i}}^{\mathrm{T}}(\mathrm{y}) \in \mathbb{R}^{\mathrm{n}}$. The exponential convergence of the observation error is established by the following theorem.

Theorem 1. Assuming that the state of the robot remains in $\mathcal{D}_{0}$, the system (14)-(16) is an exponential observer for the robot system (7)-(8) if the following conditions are satisfied (for $\mathrm{i}=1, \ldots, \mathrm{n}$ )

$$
\begin{gathered}
\mathrm{N}_{\mathrm{i}} \mathrm{T}_{\mathrm{i}}+\mathrm{L}_{\mathrm{i}} \mathrm{H}_{\mathrm{i}}=\mathrm{T}_{\mathrm{i}} \mathrm{A}_{\mathrm{i}} \\
\mathrm{g}_{\mathrm{i}}(\mathrm{z}, \mathrm{y})=\mathrm{T}_{\mathrm{i}} \mathrm{f}_{\mathrm{i}}(\hat{\mathrm{x}}) \\
{\left[\begin{array}{l}
\mathrm{T}_{\mathrm{i}} \\
\mathrm{j}_{\mathrm{i}}
\end{array}\right]\left[\begin{array}{ll}
\mathrm{j}_{\mathrm{i}}(\mathrm{y})=\mathrm{T}_{\mathrm{i}} \mathrm{h}_{\mathrm{i}}(\mathrm{y}) \\
\mathrm{M}_{\mathrm{i}} & \mathrm{E}_{\mathrm{i}}
\end{array}\right]=\left[\begin{array}{ll}
1 & 0 \\
0 & 1
\end{array}\right]} \\
\max \left(\mathrm{N}_{\mathrm{i}}\right)<-\bar{\kappa}
\end{gathered}
$$

where $\bar{\kappa}=\kappa \frac{R_{2 M}}{R_{2 m}}$, the positive scalars $R_{2 M}$ and $R_{2 m}$ are given in the proof. Then, it can be deduced that

where

$$
\|\hat{x}-x\| \leq \eta_{1} \exp \left(\eta_{2} t\right)
$$

$$
\begin{gathered}
\eta_{1}=\|\mathrm{M}\|\left(\frac{\min \left(\mathrm{N}_{\mathrm{i}}\right)}{\max \left(\mathrm{N}_{\mathrm{i}}\right)}\right)^{0.5}\|\mathrm{z}(0)-\mathrm{T} \mathrm{x}(0)\| \\
\eta_{2}=\max \left(\mathrm{N}_{\mathrm{i}}\right)+\bar{\kappa} \quad\left(\eta_{2}<0\right) .
\end{gathered}
$$

Proof. Consider the observer reconstruction error

Then, the observer error dynamic is given by

$$
\mathrm{e}=\mathrm{z}-\mathrm{T} \mathrm{x}
$$

$$
\dot{\mathrm{e}}=\mathrm{N} \text { e }+(\mathrm{N} \mathrm{T}+\mathrm{L} H-\mathrm{T} A) \mathrm{x}+(\mathrm{g}(\mathrm{z}, \mathrm{y})-\mathrm{T} f(\mathrm{x}))+(\mathrm{j}(\mathrm{y})-\mathrm{T} \mathrm{h}(\mathrm{y})) \mathrm{u} .
$$

From (17)-(19), eq. (26) becomes

$$
\dot{e}=N e+T(f(\hat{x})-f(x)) .
$$

Let $\mathrm{V}(\mathrm{e})>0$ be a Lyapunov function candidate

$$
\mathrm{V}(\mathrm{e})=\mathrm{e}^{\mathrm{T}} \mathrm{S} \text { e }
$$

where $\mathrm{S}=\mathrm{S}^{\mathrm{T}}>0$ is the solution of the Lyapunov equation

$$
\mathrm{N}^{\mathrm{T}} \mathrm{S}+\mathrm{S} \mathrm{N}=-2 \mathrm{Q}
$$

with $\mathrm{N}$ a stability matrix (according to (21)) and $\mathrm{Q}$ some diagonal positive definite matrix

$$
\mathrm{Q}=\operatorname{diag}\left(\mathrm{Q}_{\mathrm{i}}\right) \quad\left(\mathrm{Q}_{\mathrm{i}}>0\right) .
$$

The time derivative of the Lyapunov function $\mathrm{V}$ along the error dynamics (27) is

$$
\dot{V}(e)=-2 e^{T} Q e+2 e^{T} S T(f(\hat{x})-f(x)) .
$$

To bound $\dot{\mathrm{V}}$, all matrices appearing in (31) must be computed, namely eq. (17) must be solved. This can be done by parametrizing the solutions $T_{i}$ and $N_{i}$. To do that, introduce $R_{i}$ such that $\left[\begin{array}{l}R_{i} \\ H_{i}\end{array}\right] \in \mathbb{R}^{2 \times 2}$ is a regular matrix, and a scalar $\mathrm{k}_{\mathrm{i}}$ satisfying

$$
\left[\begin{array}{c}
\mathrm{T}_{\mathrm{i}} \\
\mathrm{H}_{\mathrm{i}}
\end{array}\right]=\left[\begin{array}{cc}
1 & -\mathrm{k}_{\mathrm{i}} \\
0 & 1
\end{array}\right]\left[\begin{array}{l}
\mathrm{R}_{\mathrm{i}} \\
\mathrm{H}_{\mathrm{i}}
\end{array}\right] .
$$


Then,

By the use of (20), eq. (17) becomes

$$
\mathrm{T}_{\mathrm{i}}=\mathrm{R}_{\mathrm{i}}-\mathrm{k}_{\mathrm{i}} \mathrm{H}_{\mathrm{i}} .
$$

$$
\begin{aligned}
& N_{i}-T_{i} A_{i} M_{i}=0 \\
& L_{i}-T_{i} A_{i} E_{i}=0 .
\end{aligned}
$$

The substitution of eq. (33) into (34) gives

where

$$
\begin{aligned}
\mathrm{N}_{\mathrm{i}} & =\psi_{\mathrm{i}}-\mathrm{k}_{\mathrm{i}} \Omega_{\mathrm{i}} \\
\psi_{\mathrm{i}} & =\mathrm{R}_{\mathrm{i}} \mathrm{A}_{\mathrm{i}} \mathrm{M}_{\mathrm{i}} \\
\Omega_{\mathrm{i}} & =\mathrm{H}_{\mathrm{i}} \mathrm{A}_{\mathrm{i}} \mathrm{M}_{\mathrm{i}} .
\end{aligned}
$$

The parameter in (36) can be considered as an observer gain which allows the spectrum of $\mathrm{N}_{\mathrm{i}}$ to be assigned.

Expressing the matrix $\mathrm{R}_{\mathrm{i}}$ as

and using eq. (10), eq. (33) becomes

$$
\begin{gathered}
R_{i}=\left[\begin{array}{ll}
R_{i 1} & R_{i 2}
\end{array}\right] \\
T_{i}=\left[\begin{array}{ll}
R_{i 1}-k_{i} & R_{i 2}
\end{array}\right] .
\end{gathered}
$$

From (10), (20), (33) and (39), $\mathrm{M}_{\mathrm{i}}$ is given by

$$
M_{i}=\left[\begin{array}{l}
R_{i} \\
H_{i}
\end{array}\right]-1\left[\begin{array}{l}
1 \\
0
\end{array}\right]=\left[\begin{array}{c}
0 \\
R_{i 2}^{-1}
\end{array}\right]
$$

Hence, $\mathrm{N}_{\mathrm{i}}$ can be obtained from (9), (34), (40) and (41)

$$
\mathrm{N}_{\mathrm{i}}=\frac{\mathrm{R}_{\mathrm{i} 1}-\mathrm{k}_{\mathrm{i}}}{\mathrm{R}_{\mathrm{i} 2}} .
$$

The combination of eqs (11) and (40) entails a simplification in the nonlinear part of eq. (31)

$$
T(f(\hat{x})-f(x))=\bar{R}(\alpha(\hat{x})-\alpha(x))
$$

where

$$
\begin{gathered}
\overline{\mathrm{R}}=\operatorname{diag}\left(\mathrm{R}_{\mathrm{i} 2}\right) \quad(\mathrm{i}=1, \ldots, \mathrm{n}) \\
\alpha(\mathrm{x})=\left[\ldots \alpha_{\mathrm{i}}(\mathrm{x}) \ldots . .\right]^{\mathrm{T}} .
\end{gathered}
$$

As $\mathrm{x} \in \mathcal{D}_{0}$, the property $\mathbf{P 5}$ can be rewritten as

$$
\|\alpha(\hat{\mathrm{x}})-\alpha(\mathrm{x})\| \leq \kappa\|\hat{\mathrm{x}}-\mathrm{x}\| .
$$

By the use of eq. (43), relation (31) is equivalent to

$$
\dot{\mathrm{V}}(\mathrm{e})=-2 \mathrm{e}^{\mathrm{T}} \mathrm{Q} \mathrm{e}+2 \mathrm{e}^{\mathrm{T}} \mathrm{S} \overline{\mathrm{R}}(\alpha(\hat{\mathrm{x}})-\alpha(\mathrm{x})) .
$$

A relation between the state-space error $\hat{\mathrm{x}}-\mathrm{x}$ and the reconstruction error $\mathrm{e}=\mathrm{z}-\mathrm{T} \mathrm{x}$ is obtained from (15), (20) and (25)

$$
\hat{x}-\mathrm{x}=\mathrm{Me} .
$$

By using property $\mathbf{P 5}$ and eq. (48), $\dot{\mathrm{V}}$ can be bounded as

$$
\dot{\mathrm{V}}(\mathrm{e}) \leq-2 \lambda_{\mathrm{m}}(\mathrm{Q})\|\mathrm{e}\|^{2}+2 \kappa \lambda_{\mathrm{M}}(\mathrm{S})\|\overline{\mathrm{R}}\|\|\mathrm{M}\|\|\mathrm{e}\|^{2}
$$

where $\lambda_{\mathrm{M}}\left(\right.$. ) and $\lambda_{\mathrm{m}}($.$) denote the largest and the smallest eigenvalues of the corresponding matrix. From$ (39), (41) and (44) one obtains

$$
\begin{aligned}
\|\overline{\mathrm{R}}\| & =\mathrm{R}_{2 \mathrm{M}} \\
\|\mathrm{M}\| & =\frac{1}{\mathrm{R}_{2 \mathrm{~m}}}
\end{aligned}
$$

with $R_{2 M}=\max \left(\left|R_{i 2}\right|\right)$ and $R_{2 m}=\min \left(\left|R_{i 2}\right|\right)$ where $|x|$ denotes the absolute value of $x$. Using eq. (50) and (51) in (49) gives

$$
\dot{\mathrm{V}}(\mathrm{e}) \leq-2\left(\lambda_{\mathrm{m}}(\mathrm{Q})-\bar{\kappa} \lambda_{\mathrm{M}}(\mathrm{S})\right)\|\mathrm{e}\|^{2} .
$$


with $\bar{\kappa}=\kappa \frac{R_{2 M}}{R_{2 m}}$. Then $\dot{V}$ is a negative definite function if

$$
\lambda_{\mathrm{m}}(\mathrm{Q})>\bar{\kappa} \lambda_{\mathrm{M}}(\mathrm{S}) .
$$

In order to relax the conservatism in (53), the ratio $\frac{\lambda_{m}(Q)}{\lambda_{M}(S)}$ is maximized by taking $Q=I_{n}$ (Patel and Toda, 1980). Then, the elements $Q_{i}$ of matrix $Q$ are chosen as

Therefore $\lambda_{\mathrm{M}}(\mathrm{S})$ is given by

$$
\mathrm{Q}_{\mathrm{i}}=1 .
$$

$$
\lambda_{\mathrm{M}}(\mathrm{S})=\frac{1}{\min \left|\mathrm{N}_{\mathrm{i}}\right|}=-\frac{1}{\max \left(\mathrm{N}_{\mathrm{i}}\right)} \quad\left(\mathrm{N}_{\mathrm{i}}<0\right) .
$$

It is easy to see that the inequality (53) holds if the condition (21) is satisfied. Using the Rayleigh principle (Lancaster and Tismenetsky, 1985), $\frac{\mathrm{e}^{\mathrm{T}} \mathrm{Se}}{\lambda_{\mathrm{M}}(\mathrm{S})} \leq\|\mathrm{e}\|^{2}$, and the definition of $\mathrm{V}$ (28), relation (52) becomes

$$
\dot{\mathrm{V}}(\mathrm{e}) \leq-2\left(\frac{1}{\lambda_{\mathrm{M}}(\mathrm{S})}-\overline{\mathrm{K}}\right) \mathrm{V}(\mathrm{e})
$$

This last equation proves the exponential convergence of the reduced-order observer, and its integration gives

where

$$
\mathrm{V}(\mathrm{t}) \leq \gamma_{1} \exp \left(2 \eta_{2} \mathrm{t}\right)
$$

$$
\begin{gathered}
\eta_{2}=-\left(\frac{1}{\lambda_{M}(\mathrm{~S})}-\bar{\kappa}\right)<0 \\
\gamma_{1}=(\mathrm{z}(0)-\operatorname{Tx}(0))^{\mathrm{T}}\left(-\max \left(\mathrm{N}_{\mathrm{i}}\right)\right)^{-1}(\mathrm{z}(0)-\mathrm{Tx}(0)) .
\end{gathered}
$$

Since $V(t)$ is a quadratic function of the observer reconstruction error e $(t)$, the norm of e $(t)$ can be deduced from relations (57)-(59)

$$
\|\mathrm{e}(\mathrm{t})\| \leq \gamma_{2} \exp \left(\eta_{2} \mathrm{t}\right)
$$

where

$$
\gamma_{2}=\left(\frac{\min \left(\mathrm{N}_{\mathrm{i}}\right)}{\max \left(\mathrm{N}_{\mathrm{i}}\right)}\right)^{0.5}\|\mathrm{z}(0)-\mathrm{T} \mathrm{x}(0)\|
$$

and

$$
\eta_{2}=\max \left(\mathrm{N}_{\mathrm{i}}\right)+\bar{\kappa} \quad\left(\eta_{2}<0\right) .
$$

An exponential decrease of the state observation error $(\hat{\mathrm{x}}-\mathrm{x})$ results from relations $(48)$ and $(60)$

where

$$
\|\hat{x}-x\| \leq \eta_{1} \exp \left(\eta_{2} t\right)
$$

This completes the proof of the theorem.

$$
\eta_{1}=\|\mathrm{M}\| \gamma_{2} \text {. }
$$

\subsection{Observer design procedure}

The observer design procedure can be summarized as follows:

- Choose $\mathrm{V}_{\mathrm{M}}$ and compute the Lipschitz constant $\kappa$.

- Choose $R_{i}$ such that $\left[\begin{array}{l}R_{i} \\ H_{i}\end{array}\right]$ is non-singular (for $i=1, \ldots, n$ ) and compute $\bar{\kappa}=\kappa \frac{R_{2 M}}{R_{2 m}}$.

- $\mathrm{M}_{\mathrm{i}}$ is given by (41).

- Choose $\mathrm{k}_{\mathrm{i}}$ such that $\mathrm{N}_{\mathrm{i}}(42)$ satisfies (21).

- $T_{i}$ is given by eq. (40).

- The combination of (10), (20), (33) and (42) gives

$$
\mathrm{E}_{\mathrm{i}}=\left[\begin{array}{l}
\mathrm{R}_{\mathrm{i}} \\
\mathrm{H}_{\mathrm{i}}
\end{array}\right]-1\left[\begin{array}{c}
\mathrm{k}_{\mathrm{i}} \\
1
\end{array}\right]=\left[\begin{array}{c}
1 \\
-\mathrm{N}_{\mathrm{i}}
\end{array}\right] .
$$


- $\mathrm{L}_{\mathrm{i}}$ is obtained from eq. (35)

$$
L_{i}=\left[\begin{array}{ll}
R_{i 1}-k_{i} & R_{i 2}
\end{array}\right]\left[\begin{array}{ll}
0 & 1 \\
0 & 0
\end{array}\right]\left[\begin{array}{c}
1 \\
-N_{i}
\end{array}\right]=\frac{-\left(R_{i 1}-k_{i}\right)^{2}}{R_{i 2}} .
$$

- $\mathrm{g}_{\mathrm{i}}(\mathrm{z}, \mathrm{y})$ is given by $(18), \mathrm{g}_{\mathrm{i}}(\mathrm{z}, \mathrm{y})=\mathrm{R}_{\mathrm{i} 2} \alpha_{\mathrm{i}}(\hat{\mathrm{x}})$.

- $\mathrm{j}_{\mathrm{i}}(\mathrm{y})$ is obtained from (19), $\mathrm{j}_{\mathrm{i}}(\mathrm{y})=\mathrm{R}_{\mathrm{i} 2} \mathrm{~b}_{\mathrm{i}}(\mathrm{y})$.

Remark 1. For fixed $\mathrm{R}_{\mathrm{i} 1}$ and $\mathrm{R}_{\mathrm{i} 2}$, the choice of $\mathrm{N}_{\mathrm{i}}$ can be made arbitrarily using the parameter $\mathrm{k}_{\mathrm{i}}$. Then scalars $R_{i 1}$ and $R_{i 2}$ can be considered as design parameters.

Remark 2. The stability condition (21) can be relaxed by choosing $\mathrm{R}_{2 \mathrm{M}}=\mathrm{R}_{2 \mathrm{~m}}$ which yields to $\|\overline{\mathrm{R}}\|\|\mathrm{M}\|=1$, and $\bar{\kappa}=\kappa$.

Remark 3. The stability condition (21) shows explicitly that the choice of the observer gains $\mathrm{k}_{\mathrm{i}}$ is made locally for each axis of the robot system, independently of the other axes. The unique global constraint is the Lipschitz constant $\kappa$.

Remark 4. If the state vector $\mathrm{x}=\left[\mathrm{q}^{\mathrm{T}} \dot{\mathrm{q}}^{\mathrm{T}}\right]^{\mathrm{T}}$ is chosen for the state-space representation of the robot dynamics instead of $x=\left[\ldots q_{i} \dot{q}_{i} \ldots\right]^{T}$, then the conditions (17)-(21) of Theorem 1 become

$$
\begin{gathered}
\mathrm{N} \mathrm{T}+\mathrm{L} \mathrm{H}=\mathrm{T} \mathrm{A} \\
\mathrm{g}(\mathrm{z}, \mathrm{y})=\mathrm{T} \mathrm{f}(\hat{\mathrm{x}}) \\
\mathrm{j}(\mathrm{y})=\mathrm{Th}(\mathrm{y}) \\
{\left[\begin{array}{c}
\mathrm{T} \\
\mathrm{H}
\end{array}\right]\left[\begin{array}{cc}
\mathrm{M} & \mathrm{E}
\end{array}\right]=\left[\begin{array}{cc}
\mathrm{I}_{\mathrm{n}} & 0 \\
0 & \mathrm{I}_{\mathrm{n}}
\end{array}\right]} \\
\operatorname{Re}\left(\lambda_{\mathrm{M}}(\mathrm{N})\right)<-\overline{\bar{\kappa}}
\end{gathered}
$$

where $\overline{\bar{\kappa}}=\kappa \frac{\sigma_{M}\left(\tilde{R}_{2}\right)}{\sigma_{m}\left(\tilde{R}_{2}\right)}$ with $L \in \mathbb{R}^{n \times n}, M \in \mathbb{R}^{2 n \times n}, N \in \mathbb{R}^{n \times n}, \tilde{R}_{2} \in \mathbb{R}^{n \times n}, T \in \mathbb{R}^{n \times 2 n}$. The scalars $\sigma_{M}($. and $\sigma_{\mathrm{m}}\left(\right.$. ) denote the largest and the smallest singular values of the corresponding matrix. The matrix $\widetilde{\mathrm{R}}_{2}$ in the expression of $\overline{\bar{\kappa}}$ is chosen such that $\left[\begin{array}{c}\tilde{\mathrm{R}} \\ \mathrm{H}\end{array}\right] \in \mathbb{R}^{2 \mathrm{n} \times 2 \mathrm{n}}$ is a regular matrix with

$$
\tilde{\mathrm{R}}=\left[\begin{array}{ll}
\tilde{\mathrm{R}}_{1} & \tilde{\mathrm{R}}_{2}
\end{array}\right] \text {. }
$$

In this case, the norm of the reconstruction error satisfies the following relation

where

$$
\|\hat{x}-\mathrm{x}\| \leq \bar{\eta}_{1} \exp \left(\bar{\eta}_{2} \mathrm{t}\right)
$$

and

$$
\bar{\eta}_{1}=\|\mathrm{M}\|\left(\frac{\lambda_{\mathrm{m}}(\mathrm{N})}{\lambda_{\mathrm{M}}(\mathrm{N})}\right)^{0.5}\|\mathrm{z}(0)-\mathrm{T} \mathrm{x}(0)\|
$$

$$
\bar{\eta}_{2}=\operatorname{Re}\left(\lambda_{\mathrm{M}}(\mathrm{N})\right)+\overline{\bar{\kappa}} \quad\left(\bar{\eta}_{2}<0\right) .
$$

Remark 5. This observer design can be extended to the general case of pair (A,H). First, introduce matrix $\mathrm{N}$ as in eq. (36)-(38)

where

$$
\mathrm{N}=\psi-\mathrm{k} \Omega
$$

$$
\begin{aligned}
\psi & =\text { R A M } \\
\Omega & =\text { H A M. }
\end{aligned}
$$

Note that the pairs $(\psi, \Omega)$ and $(\mathrm{A}, \mathrm{H})$ have the same unobservable poles. Indeed, by defining the following nonsingular matrices

yields

$$
\mathrm{W}=\left[\begin{array}{cc}
\mathrm{R} & -\mathrm{sk}+\mathrm{RAE} \\
\mathrm{H} & -\mathrm{sI}_{\mathrm{p}}+\mathrm{HAE} \\
0 & \mathrm{I}_{\mathrm{p}}
\end{array}\right] \text { and } \mathrm{U}=\left[\begin{array}{ll}
\mathrm{M} & \mathrm{E}
\end{array}\right],
$$




$$
\operatorname{rank}\left[\begin{array}{c}
\text { sI-A } \\
H
\end{array}\right]=\operatorname{rank} \mathrm{W}\left[\begin{array}{c}
\text { sI-A } \\
\mathrm{H}
\end{array}\right] \mathrm{U}=\operatorname{rank}\left[\begin{array}{c}
\mathrm{sI}-\psi \\
\Omega
\end{array}\right]+\mathrm{p}
$$

where $\mathrm{p}$ is the dimension of the measurement vector $\mathrm{y}$. Hence, the detectability of the pair $(\mathrm{A}, \mathrm{H})$ is necessary and sufficient to stabilize the linear part of this observer (see (29)). Then, a sufficient condition for the exponential convergence of the reduced-order observer is that the unobservable poles of the pair $(\mathrm{A}, \mathrm{H})$, i.e. the fixed modes of $\mathrm{N}$, must satisfy

$$
\operatorname{Re}\left(\lambda_{\mathrm{M}}(\mathrm{N})\right)<-\overline{\bar{\kappa}}
$$

\section{CONTROLLER DESIGN VIA THE REDUCED-ORDER OBSERVER}

This section is devoted to the stability analysis of observer-based controllers when the joint angular velocities are estimated. Two types of control laws are proposed: the so-called point-to-point control with gravity compensation, and the trajectory control (Berghuis and Nijmeijer, 1993; Lewis, et al., 1993; Nicosia and Tomei, 1990; Spong and Vidyasagar, 1989; Tagekaki and Arimoto, 1981).

\subsection{Point-to-point control with gravity compensation}

First consider a controller given by a combination of gravitation compensation and linear proportional-derivative static state feedback. This control law can be written as

$$
\Gamma=\mathrm{G}(\mathrm{q})-\mathrm{K}_{\mathrm{p}} \tilde{\mathrm{q}}-\mathrm{K}_{\mathrm{v}} \dot{\mathrm{q}}
$$

where $\mathrm{K}_{\mathrm{p}}$ and $\mathrm{K}_{\mathrm{v}}$ are diagonal positive definite matrices for proportional and derivative gains respectively, $\tilde{\mathrm{q}}=\mathrm{q}$ $\mathrm{q}_{\mathrm{d}}$ represents the position tracking error, with $\mathrm{q}$ the (measured) joint angular positions, and $\mathrm{q}_{\mathrm{d}}$ the fixed constant desired joint angular positions. Then the following equality holds

$$
\dot{\tilde{\mathrm{q}}}=\dot{\mathrm{q}} \text {. }
$$

Now, the state feedback controller (67) is replaced by the output feedback controller given by the use of the reduced-order observer (14)-(16)

$$
\Gamma=\mathrm{G}(\mathrm{q})-\mathrm{K}_{\mathrm{p}} \tilde{\mathrm{q}}-\mathrm{K}_{\mathrm{V}} \hat{\dot{q}}
$$

where $\hat{\dot{q}} \in \mathbb{R}^{\mathrm{n}}$ corresponds to the components of $\hat{\mathrm{x}}$ representing the estimated joint angular velocities. From eq. (41), (44) and (48), one obtains

Thus, the control law (68) can be written as

$$
\hat{\dot{\mathrm{q}}}=\overline{\mathrm{R}}^{-1} \mathrm{e}+\dot{\mathrm{q}}
$$

$$
\Gamma=\mathrm{G}(\mathrm{q})-\mathrm{K}_{\mathrm{p}} \tilde{\mathrm{q}}-\mathrm{K}_{\mathrm{V}} \overline{\mathrm{R}}^{-1} \mathrm{e}-\mathrm{K}_{\mathrm{v}} \dot{\mathrm{q}} .
$$

Substituting this control law into the equation of the robot dynamics (1) yields

$$
\phi(q) \ddot{\mathrm{q}}+\mathrm{C}(\mathrm{q}, \dot{\mathrm{q}}) \dot{\mathrm{q}}+\left(\mathrm{F}_{\mathrm{V}}+\mathrm{K}_{\mathrm{v}}\right) \dot{\mathrm{q}}+\mathrm{K}_{\mathrm{p}} \tilde{\mathrm{q}}+\mathrm{K}_{\mathrm{V}} \overline{\mathrm{R}}^{-1} \mathrm{e}=0 .
$$

Now, the following theorem can be stated and proved.

Theorem 2. Under conditions (17)-(20) and

$$
1+\frac{\bar{\kappa}}{\max \left(\mathrm{N}_{\mathrm{i}}\right)}>\frac{\left\|\mathrm{K}_{\mathrm{V}}\right\|^{2}}{4 \lambda_{\mathrm{m}}\left(\mathrm{F}_{\mathrm{v}}+\mathrm{K}_{\mathrm{V}}\right) \mathrm{R}_{2 \mathrm{~m}}^{2}}
$$

the controller given by (14)-(16) and (68) stabilizes the robot system (1) asymptotically at the equilibrium point $\left(\dot{\mathrm{q}}=0, \tilde{\mathrm{q}}=0, \mathrm{e}=0\right.$ ) into the positively invariant domain $\mathcal{D}_{1}$ given by

$$
\mathcal{D}_{1}=\left\{(\dot{\mathrm{q}}(0), \tilde{\mathrm{q}}(0), \mathrm{e}(0)) / \mathrm{V}_{1}(\dot{\mathrm{q}}(0), \tilde{\mathrm{q}}(0), \mathrm{e}(0))<\frac{\varphi_{1} \mathrm{~V}_{\mathrm{M}}^{2}}{2}\right\}
$$

where $\varphi_{1}$ is defined in property $\mathbf{P 1}$ and $\mathrm{V}_{1}$ is a Lyapunov function given in the proof.

Proof. Consider the Lyapunov function candidate 


$$
\mathrm{V}_{1}(\dot{\mathrm{q}}, \tilde{\mathrm{q}}, \mathrm{e})=\frac{1}{2} \dot{\mathrm{q}}^{\mathrm{T}} \phi(\mathrm{q}) \dot{\mathrm{q}}+\frac{1}{2} \tilde{\mathrm{q}}^{\mathrm{T}} \mathrm{K}_{\mathrm{p}} \tilde{\mathrm{q}}+\frac{1}{2} \mathrm{e}^{\mathrm{T}} \mathrm{Se}
$$

Using property $\mathbf{P} 2$ and eq. (43), the time derivative of $\mathrm{V}_{1}$ along the closed-loop dynamics (27) and (71) is given by

$$
\dot{\mathrm{V}}_{1}(\dot{\mathrm{q}}, \tilde{\mathrm{q}}, \mathrm{e})=-\dot{\mathrm{q}}^{\mathrm{T}}\left(\mathrm{F}_{\mathrm{V}}+\mathrm{K}_{\mathrm{V}}\right) \dot{\mathrm{q}}-\mathrm{e}^{\mathrm{T}} \mathrm{K}_{\mathrm{V}} \overline{\mathrm{R}}-1 \dot{\mathrm{q}}-\mathrm{e}^{\mathrm{T}} \mathrm{Qe}+\mathrm{e}^{\mathrm{T}} \mathrm{S} \overline{\mathrm{R}}(\alpha(\hat{\mathrm{x}})-\alpha(\mathrm{x})) .
$$

Using relations (46), (48), (54) and (56), with the fact that $(\dot{\mathrm{q}}, \tilde{\mathrm{q}}, \mathrm{e}) \in \mathcal{D}_{1}, \dot{\mathrm{V}}_{1}$ can be bounded as follows:

$$
\dot{\mathrm{V}}_{1}(\dot{\mathrm{q}}, \tilde{\mathrm{q}}, \mathrm{e}) \leq-\lambda_{\mathrm{m}}\left(\mathrm{F}_{\mathrm{v}}+\mathrm{K}_{\mathrm{V}}\right)\|\dot{\mathrm{q}}\|^{2}+\left\|\mathrm{K}_{\mathrm{V}}\right\|\left\|\overline{\mathrm{R}}^{-1}\right\|\|\mathrm{e}\|\|\dot{\mathrm{q}}\|-\left(1+\frac{\overline{\mathrm{K}}}{\max \left(\mathrm{N}_{\mathrm{i}}\right)}\right)\|\mathrm{e}\|^{2}
$$

which is equivalent to

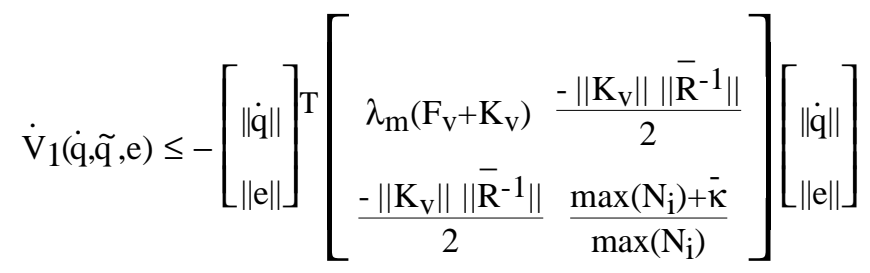

With (44) and (76), $\dot{\mathrm{V}}_{1}$ is negative semidefinite if condition (72) is satisfied.

Then the origin is a stable equilibrium point. The asymptotic stability is proved by using the LaSalle's Theorem (Vidyasagar, 1993). Indeed, consider a trajectory $(\dot{\mathrm{q}}(\mathrm{t}), \tilde{\mathrm{q}}(\mathrm{t}), \mathrm{e}(\mathrm{t}))$ in the set $\mathrm{E}=\left\{(\dot{\mathrm{q}}(\mathrm{t}), \tilde{\mathrm{q}}(\mathrm{t}), \mathrm{e}(\mathrm{t})) / \dot{\mathrm{V}}_{1}(\dot{\mathrm{q}}, \tilde{\mathrm{q}}, \mathrm{e})=0\right\}$. Then from (76), it follows that $\mathrm{e}(\mathrm{t}) \equiv 0$ and $\dot{\mathrm{q}}(\mathrm{t}) \equiv 0$. Consequently $\ddot{\mathrm{q}}(\mathrm{t}) \equiv 0$ holds, and using $(71)$, it is deduced that $\tilde{\mathrm{q}}(\mathrm{t}) \equiv 0$. Then the only trajectory contained in $\mathrm{E}$ is the origin which is asymptotically stable according to the LaSalle's Theorem.

The last part of the proof consists of checking that the inequality $\|\dot{q}(\mathrm{t})\|<\mathrm{V}_{\mathrm{M}}$ holds for all $\mathrm{t} \geq 0$ and for any initial state in $\mathcal{D}_{1}$. Consider an initial state in $\mathcal{D}_{1}$, then from the definition of this domain, the trajectory issued from this initial state remains in $\mathcal{D}_{1}$. In addition, the inequality

holds. Then one obtains

$$
\frac{1}{2}\left(\dot{\mathrm{q}}^{\mathrm{T}} \phi(\mathrm{q}) \dot{\mathrm{q}}+\tilde{\mathrm{q}}^{\mathrm{T}} \mathrm{K}_{\mathrm{p}} \tilde{\mathrm{q}}+\mathrm{e}^{\mathrm{T}} \mathrm{Se}\right)<\frac{\varphi_{1} \mathrm{~V}_{\mathrm{M}}^{2}}{2}
$$

This ends the proof.

$$
\|\dot{q}(\mathrm{t})\|<\mathrm{V}_{\mathrm{M}} \text {. }
$$

\subsection{Trajectory control}

Suppose that the robot manipulator tracks a given trajectory $\mathrm{q}_{\mathrm{d}}(\mathrm{t})$ assigned in the joint space. Assuming that $\dot{\mathrm{q}}_{\mathrm{d}}(\mathrm{t})$ and $\ddot{\mathrm{q}}_{\mathrm{d}}(\mathrm{t})$ are known, a state feedback control law is given as (Nicosia and Tomei, 1990)

$$
\Gamma=\phi(\mathrm{q}) \ddot{\mathrm{q}}_{\mathrm{d}}+\mathrm{C}(\mathrm{q}, \dot{\mathrm{q}}) \dot{\mathrm{q}}_{\mathrm{d}}+\mathrm{F}_{\mathrm{v}} \dot{\mathrm{q}}_{\mathrm{d}}+\mathrm{G}(\mathrm{q})-\mathrm{K}_{\mathrm{p}} \tilde{\mathrm{q}}-\mathrm{K}_{\mathrm{V}} \dot{\tilde{\mathrm{q}}}
$$

where $K_{\mathrm{p}}, \mathrm{K}_{\mathrm{V}}$ and $\tilde{\mathrm{q}}$ have been defined above, and $\dot{\tilde{\mathrm{q}}}=\dot{\mathrm{q}}-\dot{\mathrm{q}}_{\mathrm{d}}$ is the velocity tracking error.

If an output feedback control law is used in place of the state feedback controller (79), the estimated joint angular velocities given by the reduced-order observer are introduced in this control law. By using eq. (1) and (69), one obtains

$$
\phi(\mathrm{q}) \ddot{\tilde{\mathrm{q}}}+\mathrm{C}(\mathrm{q}, \dot{\mathrm{q}}) \dot{\mathrm{q}}-\mathrm{C}(\mathrm{q}, \dot{\dot{q}}) \dot{\mathrm{q}}_{d}+\left(\mathrm{F}_{\mathrm{V}}+\mathrm{K}_{\mathrm{V}}\right) \dot{\tilde{\mathrm{q}}}+\mathrm{K}_{\mathrm{p}} \tilde{\mathrm{q}}+\mathrm{K}_{\mathrm{V}} \overline{\mathrm{R}}^{-1} \mathrm{e}=0
$$

where $\ddot{\tilde{q}}=\ddot{q}-\ddot{q}_{d}$ is the acceleration tracking error.

Owing to property $\mathbf{P 3}$ and eq. (69), one obtains

$$
\mathrm{C}(\mathrm{q}, \dot{\mathrm{q}}) \dot{\mathrm{q}}-\mathrm{C}(\mathrm{q}, \dot{\mathrm{q}}) \dot{\mathrm{q}}_{d}=\mathrm{C}(\mathrm{q}, \dot{\mathrm{q}})\left(\dot{\mathrm{q}}-\dot{\mathrm{q}}_{d}\right)+\mathrm{C}(\mathrm{q}, \dot{\mathrm{q}}) \dot{\mathrm{q}}_{d}-\mathrm{C}\left(\mathrm{q}, \dot{\mathrm{q}}_{d}\right) \hat{\mathrm{q}}=\mathrm{C}(\mathrm{q}, \dot{\mathrm{q}}) \dot{\tilde{\mathrm{q}}}-\mathrm{C}\left(\mathrm{q}, \dot{\mathrm{q}}_{\mathrm{d}}\right) \overline{\mathrm{R}}^{-1} \mathrm{e} .
$$

Substituting eq. (81) in (80) yields

$$
\phi(\mathrm{q}) \ddot{\tilde{\mathrm{q}}}+\mathrm{C}(\mathrm{q}, \dot{\mathrm{q}}) \dot{\tilde{\mathrm{q}}}-\mathrm{C}\left(\mathrm{q}, \dot{\mathrm{q}}_{\mathrm{d}}\right) \overline{\mathrm{R}}^{-1} \mathrm{e}+\left(\mathrm{F}_{\mathrm{V}}+\mathrm{K}_{\mathrm{V}}\right) \dot{\tilde{\mathrm{q}}}+\mathrm{K}_{\mathrm{p}} \tilde{\mathrm{q}}+\mathrm{K}_{\mathrm{V}} \overline{\mathrm{R}}^{-1} \mathrm{e}=0 .
$$


The asymptotic stability of the closed-loop system given by relations (27) and (82) is proved by the following theorem.

Theorem 3. Under the conditions $\left\|\dot{q}_{d}\right\|<\frac{V_{M}}{2},(17)-(20)$ and

$$
1+\frac{\bar{\kappa}}{\max \left(\mathrm{N}_{\mathrm{i}}\right)}>\frac{\left(\mu \frac{\mathrm{V}_{\mathrm{M}}}{2}+\left\|\mathrm{K}_{\mathrm{V}}\right\|^{2}\right)^{2}}{4 \lambda_{\mathrm{m}}\left(\mathrm{F}_{\mathrm{v}}+\mathrm{K}_{\mathrm{V}}\right) \mathrm{R}_{2 \mathrm{~m}}^{2}}
$$

the equilibrium point $(\dot{\tilde{\mathrm{q}}}=0, \tilde{\mathrm{q}}=0, \mathrm{e}=0)$ of the system $(82)$ is asymptotically stable in the positively invariant domain $\mathcal{D}_{2}$ given by

$$
\mathcal{D}_{2}=\left\{(\dot{\tilde{\mathrm{q}}}(0), \tilde{\mathrm{q}}(0), \mathrm{e}(0)) / \mathrm{V}_{2}(\dot{\widetilde{\mathrm{q}}}(0), \tilde{\mathrm{q}}(0), \mathrm{e}(0))<\frac{\varphi_{1} \mathrm{~V}_{\mathrm{M}}^{2}}{8}\right\}
$$

where $\varphi_{1}$ is defined in property $\mathbf{P} \mathbf{1}$ and $V_{2}$ is a Lyapunov function given in the proof.

Proof. Let $\mathrm{V}_{2}(\dot{\tilde{\mathrm{q}}}, \tilde{\mathrm{q}}, \mathrm{e}, \mathrm{t})$ be a Lyapunov function candidate

$$
\mathrm{V}_{2}(\dot{\tilde{\mathrm{q}}}, \tilde{\mathrm{q}}, \mathrm{e}, \mathrm{t})=\frac{1}{2}\left(\dot{\tilde{\mathrm{q}}} \mathrm{T}_{\phi}(\mathrm{q}) \dot{\tilde{\mathrm{q}}}+\tilde{\mathrm{q}}^{\mathrm{T}} \mathrm{K}_{\mathrm{p}} \tilde{\mathrm{q}}+\mathrm{e}^{\mathrm{T}} \mathrm{S} \text { e }\right)
$$

By using property $\mathbf{P 2}$ and eq. (43), the time derivative of the Lyapunov function $\mathrm{V}_{2}$ along the closed-loop dynamics (27) and (82) is given by

$$
\dot{\mathrm{V}}_{2}(\dot{\tilde{\mathrm{q}}}, \tilde{\mathrm{q}}, \mathrm{e}, \mathrm{t})=-\dot{\tilde{\mathrm{q}}}^{\mathrm{T}}\left(\mathrm{F}_{\mathrm{V}}+\mathrm{K}_{\mathrm{V}}\right) \dot{\tilde{\mathrm{q}}}-\mathrm{e}^{\mathrm{T}} \mathrm{Q} \mathrm{e}-\dot{\tilde{\mathrm{q}}}^{\mathrm{T}}\left(\mathrm{C}\left(\mathrm{q}, \dot{\mathrm{q}}_{\mathrm{d}}\right)-\mathrm{K}_{\mathrm{V}}\right) \overline{\mathrm{R}}^{-1} \mathrm{e}+\mathrm{e}^{\mathrm{T}} \mathrm{S} \overline{\mathrm{R}}(\alpha(\hat{\mathrm{x}})-\alpha(\mathrm{x}))
$$

Using the relations (46), (48), (54) and (56), with the fact that $(\dot{\tilde{\mathrm{q}}}, \tilde{\mathrm{q}}, \mathrm{e}) \in \mathcal{D}_{2}, \dot{\mathrm{V}}_{2}$ can be bounded as

$$
\dot{\mathrm{V}}_{2}(\dot{\tilde{\mathrm{q}}}, \tilde{\mathrm{q}}, \mathrm{e}, \mathrm{t}) \leq-\lambda_{\mathrm{m}}\left(\mathrm{F}_{\mathrm{v}}+\mathrm{K}_{\mathrm{v}}\right)\|\dot{\tilde{\mathrm{q}}}\|^{2}-\left\|\mathrm{C}\left(\mathrm{q}, \dot{\mathrm{q}}_{\mathrm{d}}\right)-\mathrm{K}_{\mathrm{v}}\right\|\|\mathrm{e}\|\|\dot{\tilde{\mathrm{q}}}\|-\left(1+\frac{\bar{\kappa}}{\max \left(\mathrm{N}_{\mathrm{i}}\right)}\right)\|\mathrm{e}\|^{2} \text {. }
$$

Using property $\mathbf{P 4}$, the condition $\left\|\dot{\mathrm{q}}_{\mathrm{d}}\right\|<\frac{\mathrm{V}_{\mathrm{M}}}{2}$ and the triangle inequality, relation (86) becomes

$$
\dot{\mathrm{V}}_{2}(\dot{\tilde{\mathrm{q}}}, \tilde{\mathrm{q}}, \mathrm{e}) \leq-[\|\dot{\tilde{\mathrm{q}}}\|\|\mathrm{e}\|]\left[\begin{array}{cc}
\lambda_{\mathrm{m}}\left(\mathrm{F}_{\mathrm{V}}+\mathrm{K}_{\mathrm{V}}\right) & \frac{-\left\|\overline{\mathrm{R}}^{-1}\right\|\left(\left\|\mathrm{K}_{\mathrm{V}}\right\|+\frac{\mu \mathrm{V}_{\mathrm{M}}}{2}\right)}{2} \\
\frac{-\left\|\mathrm{R}^{-1}\right\|\left(\left\|\mathrm{K}_{\mathrm{V}}\right\|+\frac{\mu \mathrm{V}_{\mathrm{M}}}{2}\right)}{2} & \frac{\max \left(\mathrm{N}_{\mathrm{i}}\right)+\bar{\kappa}}{\max \left(\mathrm{N}_{\mathrm{i}}\right)}
\end{array}\right][\dot{\mathrm{q}}\|\| \mathrm{e} \|] \text {, }
$$

Then, using (44) and (87), $\dot{\mathrm{V}}_{2}$ is negative semidefinite if condition (83) is verified.

From (87), the equilibrium point is stable which implies that the trajectories of the closed-loop system are bounded. Then, using (82) $\ddot{\tilde{\mathrm{q}}}(\mathrm{t})$ is bounded. In order to prove the asymptotic stability of the origin, it must be established that $\lim _{\mathrm{t} \rightarrow+\infty}(\dot{\tilde{\mathrm{q}}}(\mathrm{t}), \tilde{\mathrm{q}}(\mathrm{t}), \mathrm{e}(\mathrm{t}))=0$. Using the Barbalat's Lemma (Nicosia and Tomei, 1990), one obtains $\lim _{\mathrm{t} \rightarrow+\infty} \dot{\mathrm{V}}_{2}(\dot{\tilde{\mathrm{q}}}(\mathrm{t}), \tilde{\mathrm{q}}(\mathrm{t}), \mathrm{e}(\mathrm{t}), \mathrm{t})=0$ since $\mathrm{V}_{2} \geq 0, \dot{\mathrm{V}}_{2} \leq 0$ and $\dot{\mathrm{V}}_{2}$ uniformly continuous. From (87), it follows that $\lim _{\mathrm{t} \rightarrow+\infty}(\mathrm{e}(\mathrm{t}))=0$ and $\lim _{\mathrm{t} \rightarrow+\infty}(\dot{\tilde{\mathrm{q}}}(\mathrm{t}))=0$. Using the time derivative of $(82)$ yields the boundedness of $\ddot{\widetilde{\mathrm{q}}}(\mathrm{t})$, then $\ddot{\widetilde{\mathrm{q}}}(\mathrm{t})$ is uniformly continuous. Now according to the Barbalat's Lemma, $\lim _{\mathrm{t} \rightarrow+\infty}(\ddot{\widetilde{\mathrm{q}}}(\mathrm{t}))=0$ is deduced from $\lim _{\mathrm{t} \rightarrow+\infty}(\dot{\tilde{\mathrm{q}}}(\mathrm{t}))=0$ and the uniform continuity of $\ddot{\tilde{q}}(t)$. Finally the use of $(82)$ leads to $\lim _{t \rightarrow+\infty}(\tilde{q}(t))=0$.

To end the proof, it must be shown that the inequality $\|\dot{q}(\mathrm{t})\|<\mathrm{V}_{\mathrm{M}}$ holds for all $\mathrm{t} \geq 0$ and for any initial state in $\mathcal{D}_{2}$. Consider an initial state in $\mathcal{D}_{2}$, then from the definition of this domain, the trajectory issued from this initial state remains in $\mathcal{D}_{2}$. In addition, the inequality

holds. It follows that

$$
\dot{\tilde{\mathrm{q}}}(\mathrm{t})^{\mathrm{T}} \phi(\mathrm{q}) \dot{\tilde{\mathrm{q}}}(\mathrm{t})+\tilde{\mathrm{q}}(\mathrm{t})^{\mathrm{T}} \mathrm{K}_{\mathrm{p}} \tilde{\mathrm{q}}(\mathrm{t})+\mathrm{e}(\mathrm{t})^{\mathrm{T}} \operatorname{Se}(\mathrm{t})<\frac{\varphi_{1} \mathrm{~V}_{\mathrm{M}}^{2}}{4}
$$


Then one obtains

$$
\dot{\tilde{\mathrm{q}}}(\mathrm{t})^{\mathrm{T}} \phi(\mathrm{q}) \dot{\tilde{\mathrm{q}}}(\mathrm{t})<\frac{\varphi_{1} \mathrm{~V}_{M}^{2}}{4} .
$$

$$
\left\|\dot{q}(t)-\dot{q}_{d}(t)\right\|<\frac{V_{M}}{2} .
$$

Since $\left\|\dot{\mathrm{q}}_{\mathrm{d}}(\mathrm{t})\right\|<\frac{\mathrm{V}_{\mathrm{M}}}{2}$, the triangle inequality applied to (90) yields $\|\dot{\mathrm{q}}(\mathrm{t})\|<\mathrm{V}_{\mathrm{M}}$. This completes the proof.

Remark 6. With relation (21), one obtains

$$
0<1+\frac{\bar{\kappa}}{\max \left(\mathrm{N}_{\mathrm{i}}\right)}<1
$$

independently of the choice of the scalars $R_{i 2}(i=1, \ldots, n)$. Then, with an appropriate choice of $R_{2 m}$, the closedloop stability conditions (72) and (83) hold if Theorem 1 is satisfied and if the state feedback laws (67) and (79) are asymptotically stable, i.e. $\mathrm{K}_{\mathrm{p}}>0$ and $\mathrm{K}_{\mathrm{V}}>0$ (see (72), (73), (83) and (84)). The pole assignment being independent of $\mathrm{R}_{2 \mathrm{~m}}$ (see Remark 1), this corresponds to the separation principle for the case under consideration.

\section{SIMULATION RESULTS}

Both observer-based controllers of Sections 4.1 and 4.2 have been tested by simulations referring to the two degrees-of-freedom rigid robot manipulator described by Berghuis and Nijmeijer (1993) and given in the Appendix. In Figs 1 to 8 the solid line is related to controllers using the proposed reduced-order observer, and the dotted and dashed lines are related to the controllers using the full-order observer given in (Deza and Gauthier, 1991) and (Deza, et al., 1993). In order to compare these controllers, the poles of the linear part of the reducedorder observer are assigned to -30 (solid line [1]), while those of the full-order observer are assigned to -30 (dashed line [2]) and -60 (dotted line [3]), (which can be obtained by choosing the design parameter $\theta$ given in (Deza and Gauthier, 1991) and (Deza, et al., 1993) equal to 30 and 60). Figures 1 and 2 show the angular velocity observer errors for links 1 and 2 . It can be noted that the reduced-order observer presents a dynamic behaviour better than the full-order observer one for a same pole assignment. In order to obtain similar performances, the poles of the full-order observer must be chosen twice as large as those of the reduced-order observer. 


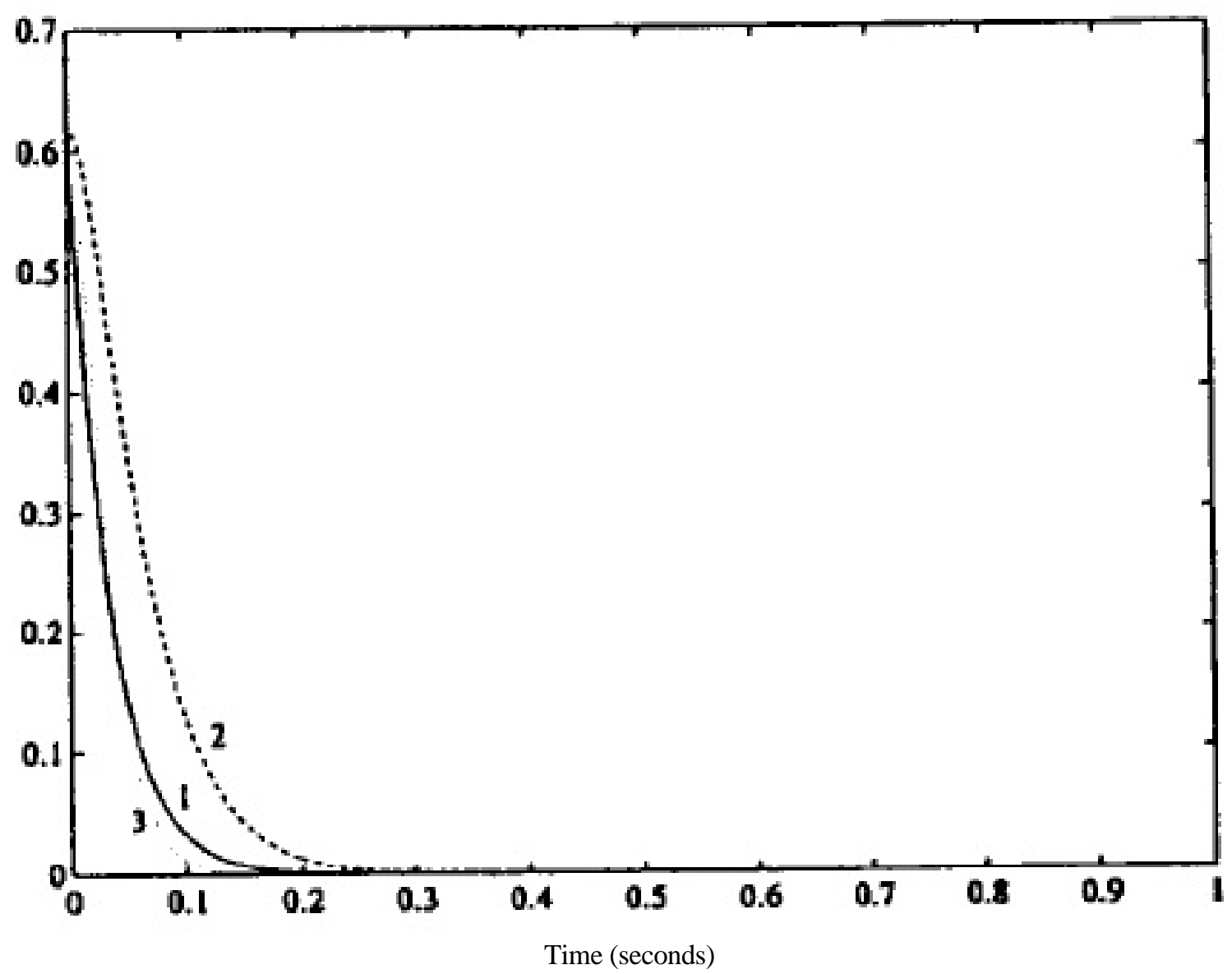

Fig. 1. Observer convergence for the first link.

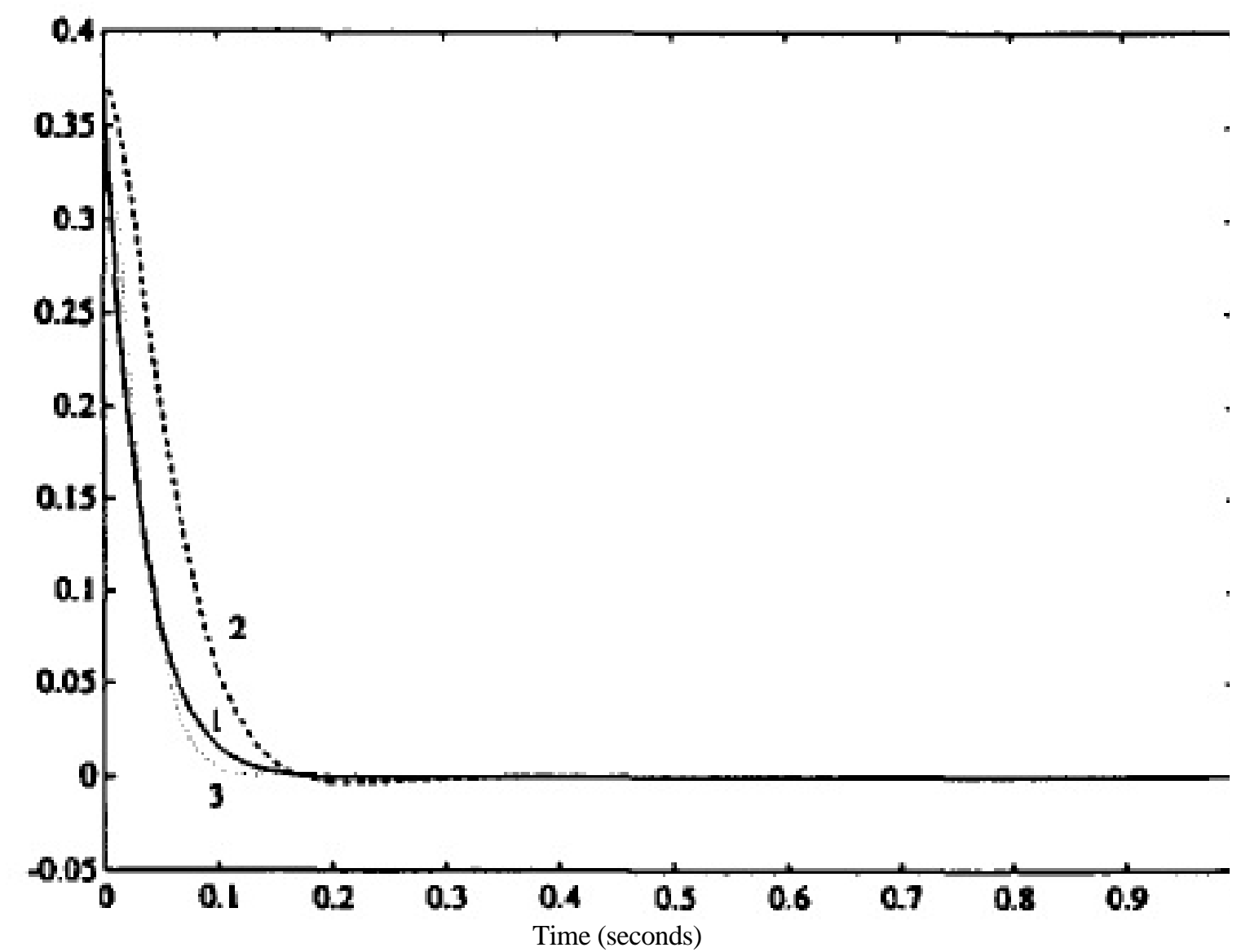

Fig. 2. Observer convergence for the second link. 
Figures 3 and 4 show the responses obtained for the two links with point-to-point output feedback control (Section 4.1). Although the responses in all cases seem similar, a change of the curve scale shows that the performances obtained are in keeping with those of Figs 1 and 2.

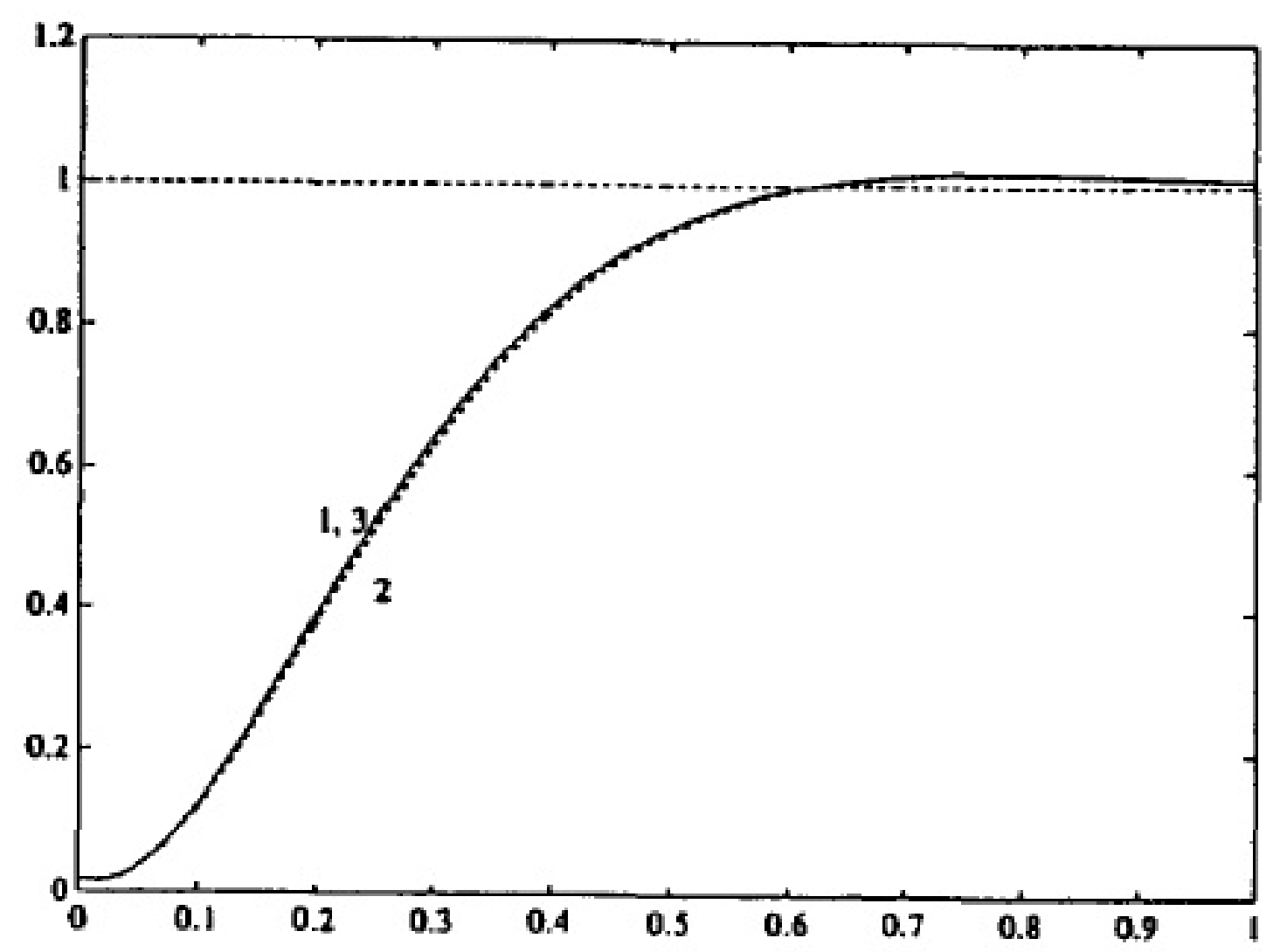

Time (seconds)

Fig. 3. Responses (first link) with observer-based point-to-point control law with gravity compensation.

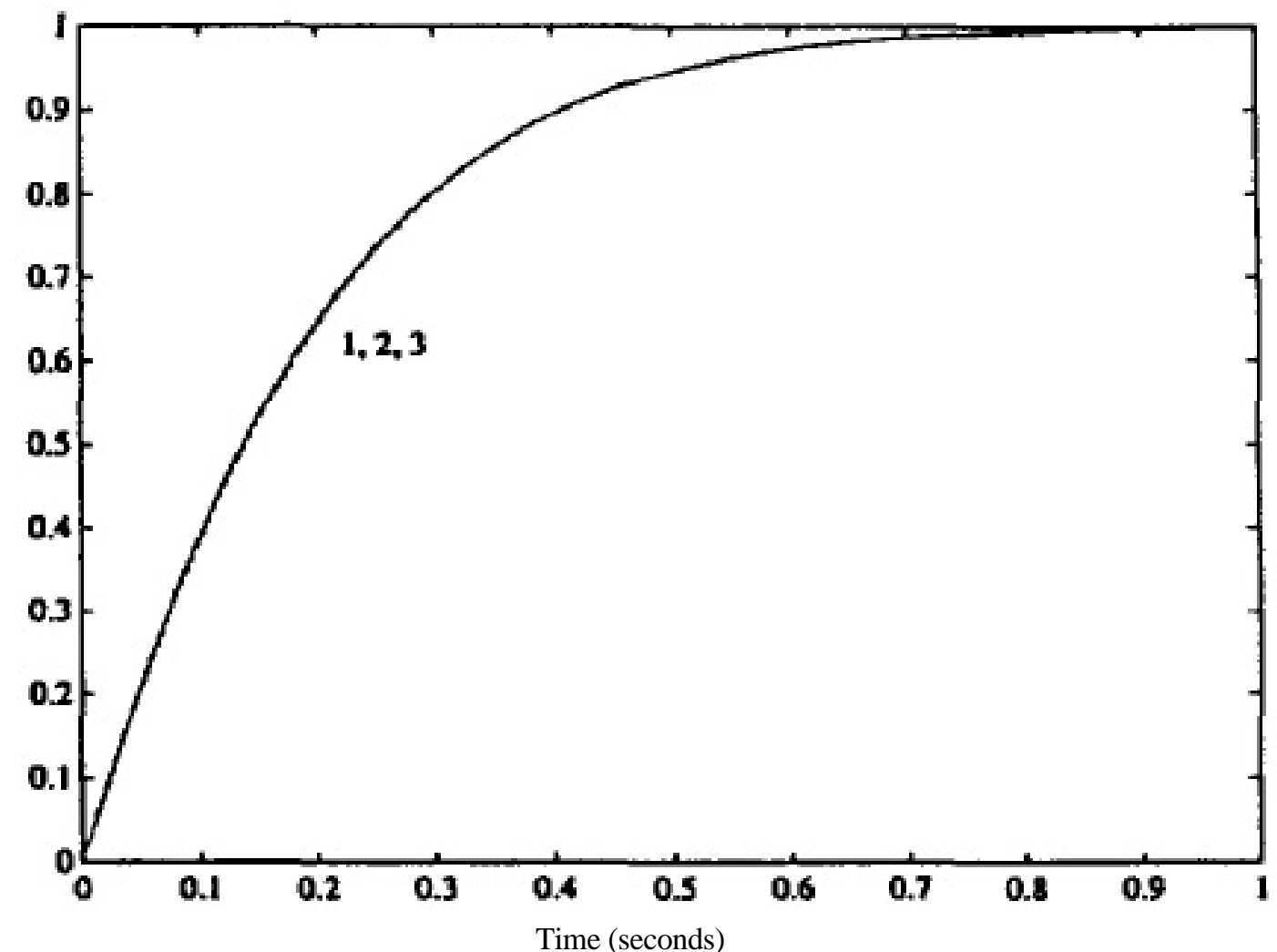

Fig. 4. Responses (second link) with observer-based point-to-point control law with gravity compensation. 
Figures 5 and 6 represent the position tracking errors for both links (Section 4.2).

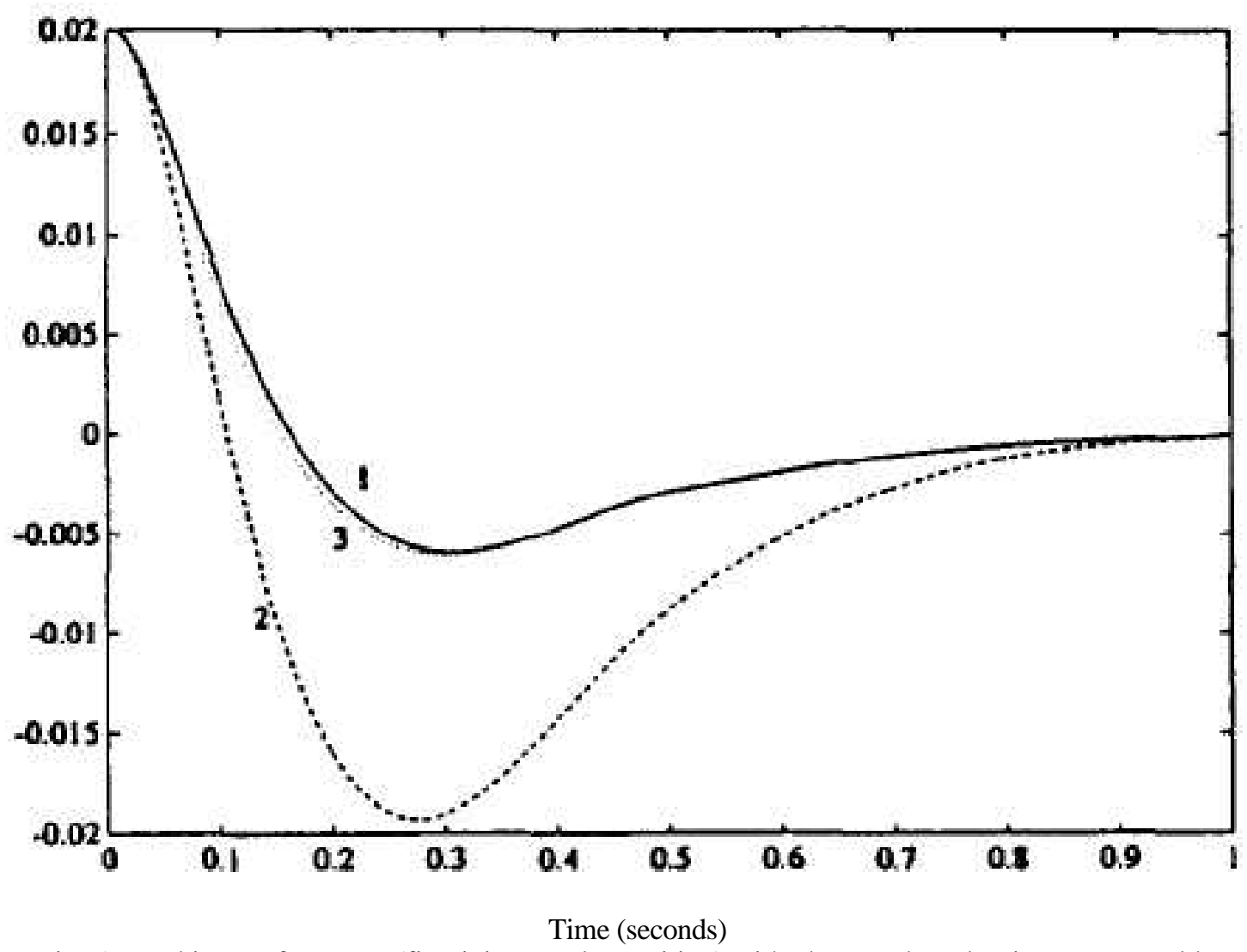

Fig. 5. Tracking performance (first joint angular position) with observer-based trajectory control law.

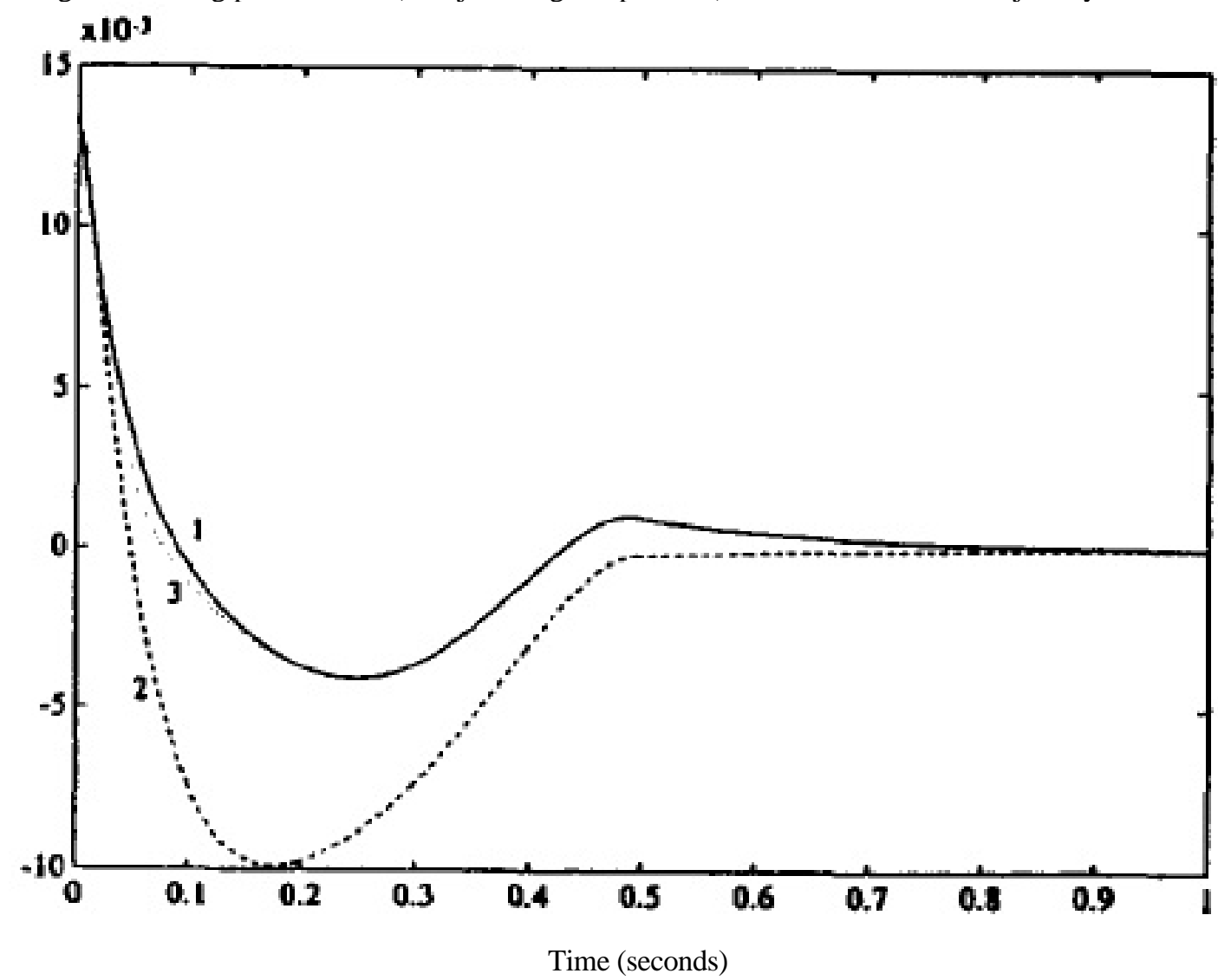

Fig. 6. Tracking performance (second joint angular position) with observer-based trajectory control law. 
Figures 7 and 8 represent the velocity tracking error with trajectory output feedback control (Section 4.2). For these figures, the tracking error is greater with the full-order observer for the same pole assignment than in the case of the reduced-order observer.

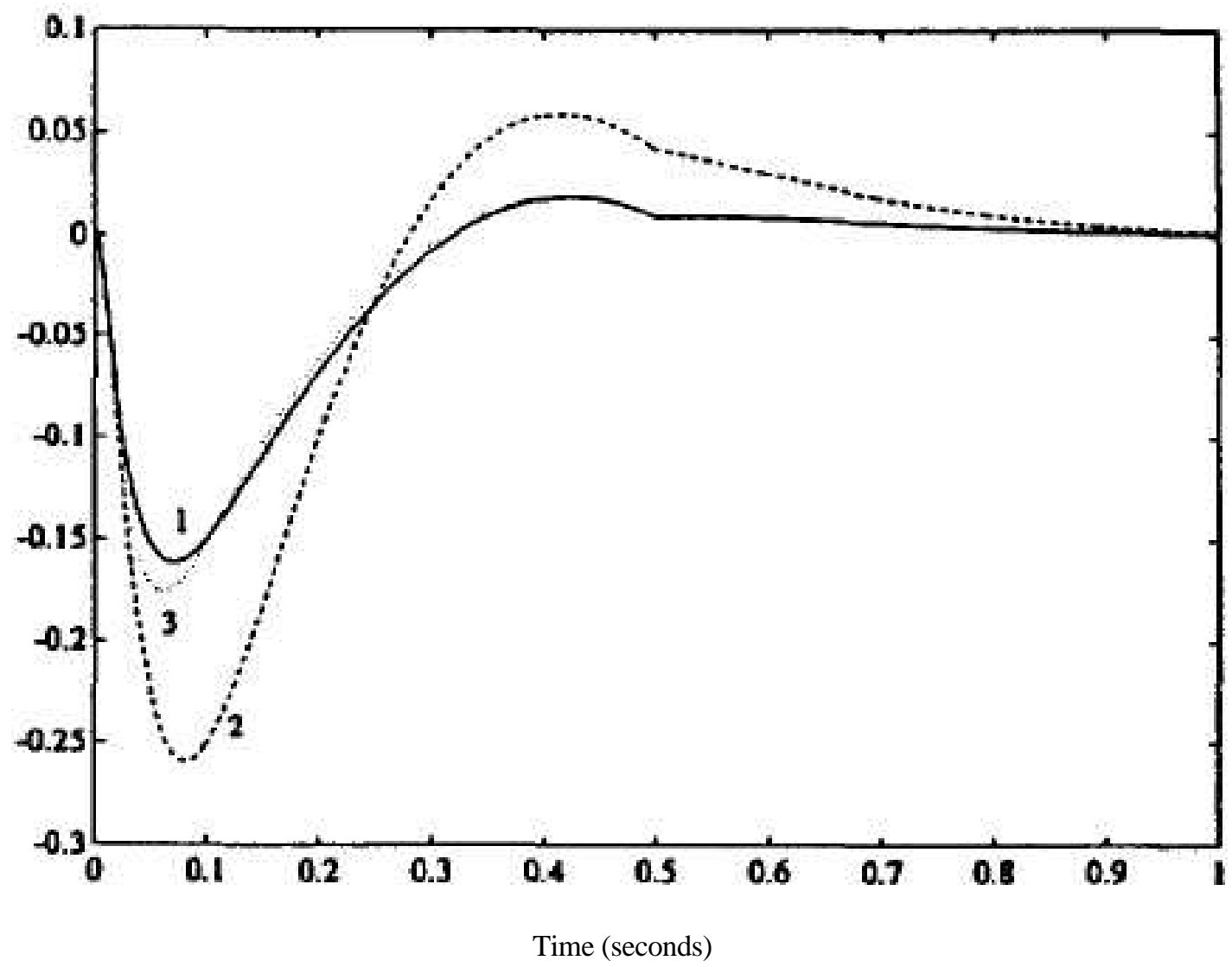

Fig. 7. Tracking performance (first joint angular velocity) with observer-based trajectory control law.

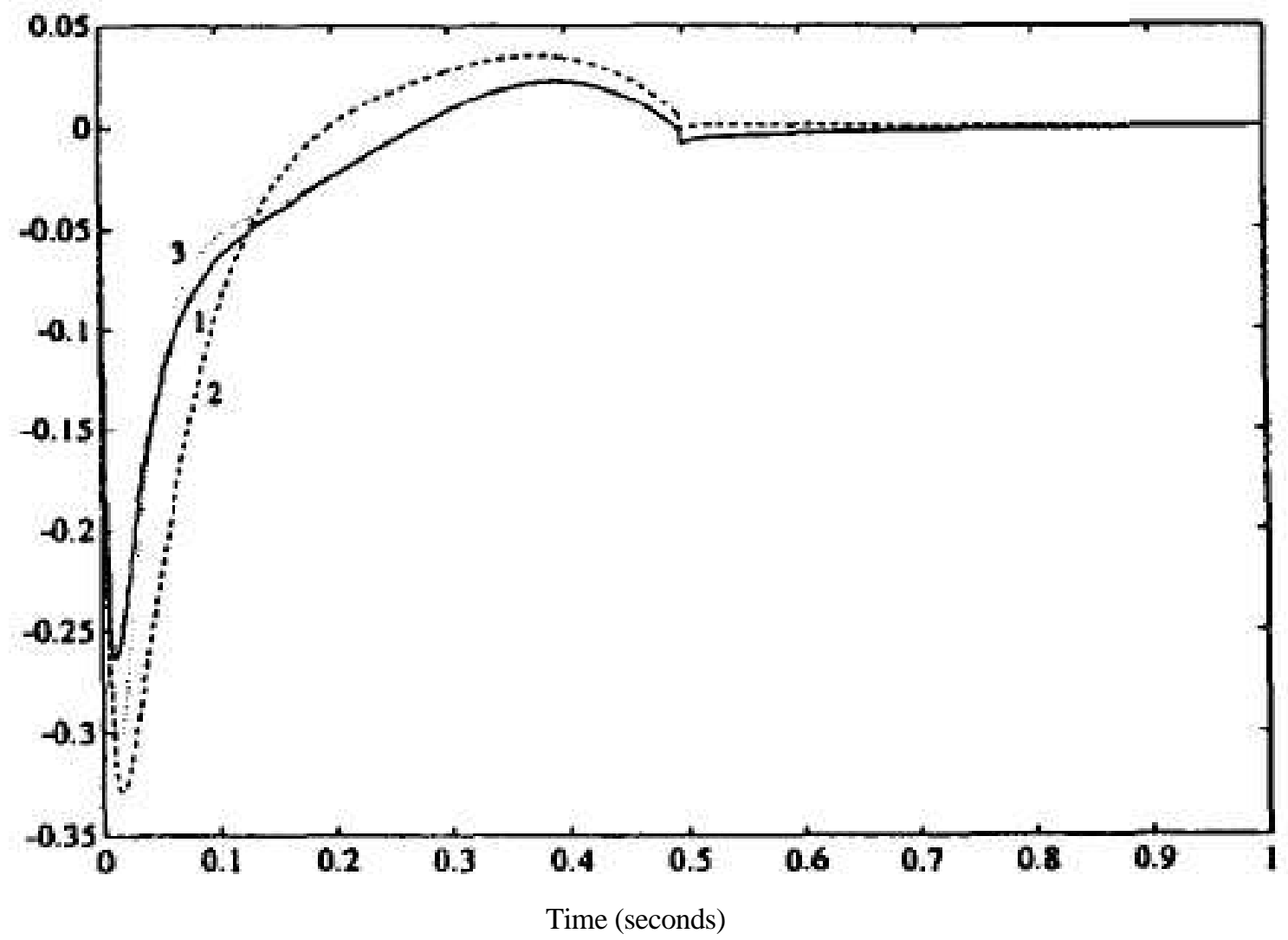

Fig. 8. Tracking performance (second joint angular velocity) with observer-based trajectory control law. 
Through these simulations, it can be seen that the proposed observer provides better closed-loop performance for both controllers for the robot manipulator than the full-order observer developed by Deza and Gauthier (1991) and Deza, et al., (1993).

\section{CONCLUSION}

This paper has proposed a new exponential reduced-order observer for a class of nonlinear systems, and has given the sufficient conditions for its exponential convergence. This observer has been used with two types of state feedback controllers for robot manipulators: point-to-point control with gravity compensation and trajectory control. Sufficient conditions for the closed-loop asymptotic stability are given. A simulation example shows the efficiency of the reduced-order observer-based controller design.

\section{REFERENCES}

Berghuis, H. and H. Nijmeijer (1993). Global regulation of robots using only position measurements. Syst. Cont. Let., 21, 289-293.

Canudas de Wit, C., N. Fixot and K.J. Åström (1992). Trajectory tracking in robot manipulators via nonlinear estimated state feedback. IEEE Trans. Rob. Aut., 8, 138-144.

Deza, F. and J.P. Gauthier (1991). A simple and robust nonlinear estimator. IEEE Conf. Dec. Cont., Brighton, 453-454.

Deza, F., D. Bossanne, E. Busvelle, J.P. Gauthier and D. Rakotopara (1993). Exponential observers for nonlinear systems. IEEE Trans. Aut. Cont., 38, 482-484.

Khelfi, M.F., M. Zasadzinski, M. Darouach, H. Rafaralahy and E. Richard (1995). Reduced-order observer-based point-to-point and trajectory controllers for robot manipulators. Int. IFAC Conf. on Syst. Structure Cont., Nantes, 376-381.

Koditschek, D.E. (1984). Natural motion of robot arms. IEEE Conf. Dec. Cont., Las Vegas.

Lancaster, P., and M. Tismenetsky (1985). The theory of matrices - Second Edition (Academic Press).

Lewis, F.L., C.T. Abdallah and D.M. Dawson (1993). Control of robot manipulators (Macmillan).

Nicosia, S. and P. Tomei (1990). Robot control by using only joint position measurements. IEEE Trans. Aut. Cont., 35, 1058-1061.

Patel, R.V. and M. Toda (1980). Quantitative measures of robustness for multivariable systems. Joint Aut. Cont. Conf., San Francisco.

Spong, M.W. and M. Vidyasagar (1989). Robot dynamics and control (John Willey \& Sons).

Takegaki, M. and S. Arimoto (1981). A new feedback method for dynamic control of manipulators. ASME J. Dyn. Syst. Meas. Cont., 102, 119-125.

Vidyasagar, M. (1993). Nonlinear systems analysis - Second Edition (Prentice-Hall International).

\section{APPENDIX}

The robot under consideration (Berghuis and Nijmeijer, 1993) moving in the vertical plane is represented in Fig. 9 and is characterized by

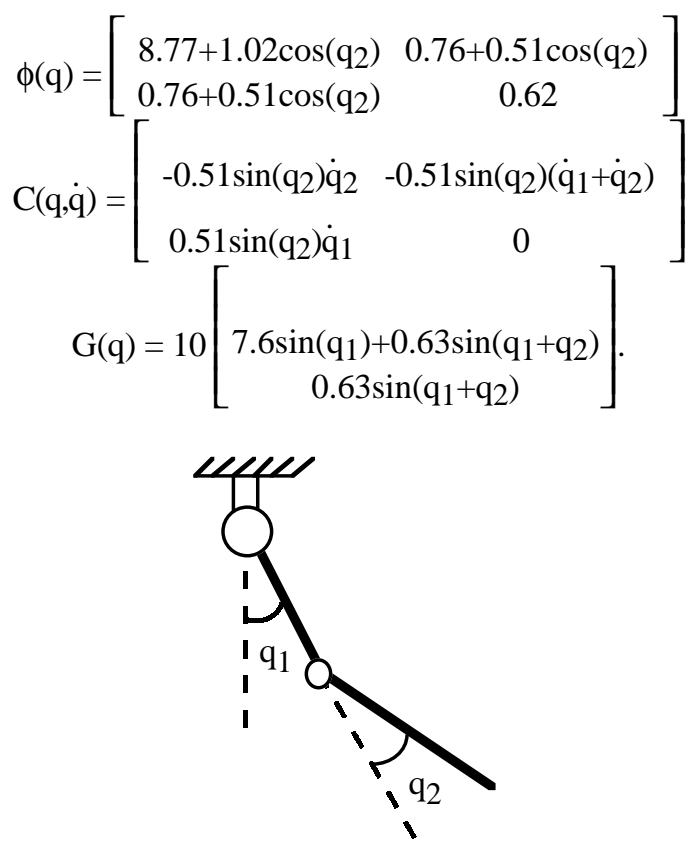

Fig. 9. Two degrees-of-freedom robot system. 